\title{
REVISIONES
}

\section{Ecomuseos y mapas de comunidad: un recurso para la enseñanza de la historia y el patrimonio}

\author{
Eco-museums and community maps: \\ a resource for teaching history and heritage
}

\author{
Beatrice Borghi \\ Dipartimento di Scienze dell'Educazione, Università di Bologna \\ Correo electrónico: b.borghi@unibo.it
}

\section{RESUMEN}

La museología, disciplina que, con la museografìa, se ocupa de museos, ha estudiado durante años los museos tradicionales, aquellos dedicados a colecciones históricas particulares y definidas, es decir, solo al patrimonio material, el único oficialmente reconocido. En el artículo se mostrará cómo los mapas son mucho más que una representación cartográfica, ya que expresan la idea del lugar, resumen la visión del mundo de aquellos que lo habitan y al mismo tiempo localizan los símbolos del territorio y los confines naturales dentro de los que la comunidad se reconoce. En este sentido, la construcción de un mapa de comunidad puede representar una eficaz herramienta de reflexión democrática para un aprendizaje activo de la historia y para una educación al patrimonio y a la ciudadanía en los contextos escolares. En particular, a través de prácticas didácticas en los contextos escolares ha surgido que el proceso de trazado de un mapa pone en juego las relaciones entre generaciones diferentes, portadoras de experiencias, memorias y valores totalmente disímiles, pero de todas formas capaces de dialogar, a través de la propuesta de prácticas caracterizadas por la empatía, la lealtad, la aceptación, la escucha activa, la solidaridad y la cooperación.

Palabras clave: ecomuseo, mapas de comunidad, identidad, ciudadanía, patrimonio.

\section{ABSTRACT}

Museology, discipline that along with museography deals with museums, has studied for years traditional museums dedicated to special and defined historical collections of material heritage as the only one which is officially recognized. This article shows how maps are more than just a cartographic representation because they express the idea of the site, summarize the world vision of those who live there and, at the same time, identify the territory symbols and the natural boundaries in which the community recognizes itself. In this sense, building a community map represents a democratic reflection for the active learning of history and for the education of heritage and citizenship in school contexts. In particular, through didactic practices, the mapping process puts into play the relationships between different generations, which carry experiences, memories and values that are completely dissimilar, but are still able to dialogue through the proposal of practices based on empathy, loyalty, acceptance, active listening, solidarity and cooperation.

Keywords: ecomuseum, community maps, identity, citizenship, heritage. 


\section{LOS ECOMUSEOS: PARA UNA EDUCACIÓN COMUNITARIA AL PATRIMONIO}

Los ecomuseos, concebidos inicialmente como herramientas para proteger las huellas de las sociedades rurales en un momento en que la urbanización, las nuevas adquisiciones tecnológicas y los consiguientes cambios sociales representaban un riesgo real de completo olvido de un patrimonio cultural milenario, han asumido con el paso del tiempo un nuevo valor fundamental en la afirmación del fenómeno, introducido en la museología y que subraya la creciente participación y la implicación activa de la comunidad en la conservación del patrimonio cultural.

Mientras que el museo tradicional se ocupa de la adquisición, conservación, estudio, valorización y exhibición de testimonios materiales del hombre y de su ambiente, el ecomuseo centra la atención en el territorio como elemento intrínsecamente ligado a los procesos sociales. Además, a diferencia del museo tradicional que se caracteriza por la exposición de su contenido a un público, el ecomuseo hace de la población misma uno de sus elementos relevantes. El análisis realizado por De Varine es propuesto a continuación con una tabla de más inmediata comprensión:

Tabla 1. Comparativa museo ecomuseo

\begin{tabular}{|l|c|}
\hline \multicolumn{1}{|c|}{ MUSEO } & ECOMUSEO \\
\hline Colección & Patrimonio \\
\hline Inmueble & Territorio \\
\hline Público & Población \\
\hline
\end{tabular}

Fuente: IRES Piemonte (2000, p. 11).

Georges Henri Rivière, con De Varine sobre la elaboración de una definición de ecomuseo, ha propuesto una metáfora sugestiva: un ecomuseo es

[...] espejo en el que la población se contempla para reconocerse, donde busca la explicación del territorio en el que está enraizada y en el que se sucedieron todos los pueblos que la precedieron, en la continuidad o discontinuidad de las generaciones. Un espejo que la población ofrece a sus huéspedes para hacerse entender mejor, en el respeto de su trabajo, de sus formas de comportamiento y de su identidad. (Rivière, 1989/1992, p. 7).

Asimismo, ha intentado captar los elementos que, al caracterizar el ecomuseo, definen mejor su identidad: este es

[...] una expresión del hombre y de la naturaleza, una expresión del tiempo, una interpretación del espacio, un laboratorio, ya que contribuye al estudio del pasado y del contemporáneo de la población y de su ambiente, un centro de conservación, en la medida en que ayuda a preservar y valorizar el patrimonio natural y cultural de la población, una escuela. (Rivière, 1989/1992, p. 7). 
Otros estudiosos han trabajado en la propuesta de definiciones cada vez más exhaustivas, entre ellos Peter Davis (Davis, 1999), quien ha identificado cinco criterios fundamentales de la identidad ecomuseística:

- La extensión del territorio más allá de los confines del museo, es decir, la no circunscripción dentro de un lugar físico definido y único.

- La interpretación fragmented-site e in situ, es decir, la promoción de los objetos o de las actividades de interés directamente en el contexto de origen.

- La cooperación y el partenariado en vez de la propiedad de los sectores, es decir, el reconocimiento de la población como poseedora y usuaria de su patrimonio.

- La implicación de la comunidad local y de los habitantes en las actividades del museo, considerado como lugar de intercambio, de actividades compartidas y negociadas.

- La interpretación de tipo holístico e interdisciplinario, es decir, no especializada, capaz de conectar varios niveles y visiones.

Davis, sintetizando, sitúa al ecomuseo en el centro de tres esferas: museística, ambiental y comunitaria. Hoara Kazuochi (Hoara, 1988), retomando la definición de Davis, que puede resumirse en la imagen (Figura 1), profundiza en la descripción de las tres esferas:

- $\quad$ El aspecto museístico se ocupa de la conservación de la naturaleza y las tradiciones.

- $\quad$ El aspecto ambiental se encarga de las diferentes formas que el patrimonio cultural adopta en una determinada región, incluidas las conformaciones medioambientales, las tradiciones culturales, etc.

- $\quad$ El aspecto comunitario se refiere a la participación de la población en la gestión y en la utilización del patrimonio cultural.

Figura 1. Concepto de ecomuseo representado por la interconexión de tres esferas

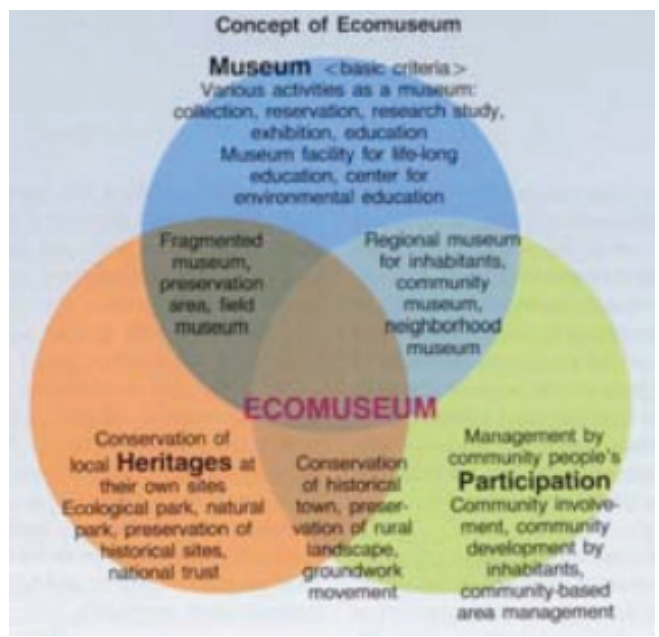

Fuente: Davis (1999) y Hoara (1988). 
La definición oficial de ecomuseo adoptada por ICOM, International Council of Museums, fundada en la tríada patrimonio-territorio-comunidad identificada como síntesis de las propuestas anteriores, es la de museo basado en un pacto con el cual una comunidad cuida de un territorio (Maggi, 2002). Esta definición implica, en primer lugar, una asunción de responsabilidad por parte de los promotores del ecomuseo, si bien no vinculada por normas formales. En segundo lugar, reivindica el papel activo de la población, llamada a participar colaborando con las instituciones locales. En tercer lugar, define un objetivo preciso, el cuidado del territorio que, lejos de ser de fácil realización, requiere un compromiso a largo plazo. Por último, desvela la complejidad de los significados inherentes al concepto de territorio, constituido por una multitud de elementos: ambientales, culturales, sociales, etc. Volviendo a la pregunta qué es un ecomuseo, podríamos aventurar una definición, que, sin pretender ser unívoca del concepto, podríamos resumir en la narración de una historia, de un espacio, de una relación entre la población y su ambiente de vida (eco, del griego òikos=casa), un museo vivo, vivido, en continuo movimiento y re-definición.

\section{LA PARTICIPACIÓN DE LA COMUNIDAD Y EL CUIDADO DEL TERRITORIO}

El proyecto teórico del ecomuseo de Rivière está caracterizado por una visión diacrónica que lo define en la reconstrucción de las dinámicas históricas del territorio y como centro de reflexión sobre la proyectualidad social del presente comunitario, bajo un punto de vista de desarrollo sostenible. Por consiguiente, los ecomuseos se prefiguran como posibles "actores de desarrollo social", fundamentos para la elaboración de las representaciones del pasado con el fin de registrar los elementos de dinamismo, cambio y conflicto, por tanto muy lejos de una reconstrucción pasadista edulcorada de "los buenos tiempos del pasado". Sin embargo, hemos de detectar algunos puntos de fragilidad que tienen que ver con la dificultad del "modelo" utópico del ecomuseo, que implican, por un lado, saber mantener altos los niveles de implicación de la población, y por otro, limitar las fricciones que a veces pueden presentarse entre los gestores del patrimonio, los diferentes actores y los grupos sociales, entre los cuales los mismos museos; y por último, contener el riesgo de que un paisaje sea tratado con soluciones simplistas, aplanadas sobre imágenes estereotipadas y nostálgicas.

$\mathrm{Si}$ confirmamos el ecomuseo como modelo orientativo social, podemos afirmar por consiguiente que este es una herramienta al servicio de la ciudadanía y, si declinamos el asunto en el ámbito de una reflexión metodológica sobre la enseñanza de la historia, el mismo se convierte en un lugar de reflexión, centro de elaboración crítica de la memoria histórica y de construcción de la identidad local, en la que se confrontan saberes expertos y saberes contextuales (Sturani, 2009) y gestor de actividad del patrimonio.

En particular, en la óptica de una educación a la ciudadanía activa, se considera que la participación de las escuelas de cualquier orden y grado en la reconstrucción de las dinámicas históricas del territorio de las que el ecomuseo define el lugar de encuentro y reflexión compartida, puede manifestarse ulteriormente a través de la determinación de algunas acciones dirigidas a consolidar la relación entre museo, paisaje y vivir juntos: sobre todo a través de un acercamiento al paisaje entendido como un sistema "en movimiento", dinámico, fruto de la sedimentación en el tiempo de acciones ecológicas, sociales, del actuar del hombre en el espacio; comprender que el paisaje es espejo de la sociedad que lo produce y, por tanto, está fuertemente vinculado a las percepciones y a las representaciones 
conectadas a las prácticas y a la materialidad del paisaje mismo. Dos premisas que proponen el mapa de comunidad como herramienta capaz de construir la conciencia de la complejidad de los procesos y el conjunto de los significados a los que el paisaje remite y ofrecerse como base para un proyecto de gestión de su cambio (Sturani, 2009).

El conocimiento del territorio, y del patrimonio heredado del pasado, implica, en nuestra opinión, un acercamiento a la comunidad, de la que los mapas son una expresión, que puede orientar la representación de la comunidad misma y sus memorias, pero también, y sobre todo, a una profundización histórica encaminada a comprender los procesos que han dado vida al paisaje "encerrado" en un ecomuseo y a la comunidad.

En síntesis, el estudio de la comunidad no requiere una profundización histórica, ya que se limita a las representaciones comunitarias y a sus memorias. Estos últimos son aspectos importantes en el estudio escolar del territorio, pero no lo agotan: el estudio y la enseñanza de la historia vinculados a la realidad del ecomuseo podrían prever también el conocimiento de los procesos que han dado vida a la realidad ecomuseística (Musci, 2015; Sturani \& Pressenda, 2015). Es siguiendo esta trayectoria que el ecomuseo puede realmente restituir la complejidad de los procesos, de los significados a los que remite el paisaje natural y proponerse como proyecto de gestión de su cambio.

Considerando el ecomuseo como un espejo que la población ofrece a sus huéspedes (Rivière, 1989/1992), el papel asumido por la población de la comunidad es condición imprescindible para su participación. El conocimiento del territorio, en parte ya arraigado en aquellos que viven en él y en parte construido en el tiempo, ha de ser un conocimiento compartido, por todos, sobre la identidad comunitaria. Como subraya Hugues de Varine (De Varine, 2010), es necesario poner a los ciudadanos en condiciones de recuperar la confianza en sí mismos. En efecto, en los países donde rige la democracia indirecta, es decir, donde el poder está confiado a representantes elegidos cada cuatro o cinco años, los ciudadanos desarrollarían la tendencia a delegar. Delegar elecciones y decisiones sobre el territorio en que se vive, sobre el patrimonio cultural que pertenece legítimamente a la totalidad de la población, equivale a no participar, a no actuar, a aceptar pasivamente, a no ejercer lo que en realidad sería un derecho. Así pues, según De Varine, es necesario proporcionar a los ciudadanos los conocimientos y las competencias que les hagan capaces de asumirse la responsabilidad del cuidado y la protección del patrimonio cultural. Se trata de conocimientos relativos al valor del patrimonio, a su estado actual, a su historia, a sus perspectivas futuras de evolución, y de competencias prácticas y operativas para su gestión. Solamente así, todos y cada uno podrán ser realmente garantes del patrimonio cultural.

La participación, identificada por De Varine como una de las "buenas prácticas" del desarrollo sostenible (De Varine, 2010, p. 3), debe ser considerada como tal solo si es generalizada, es decir, si efectivamente puede ser ejercida por la totalidad de la población, sin excluir a nadie. En caso contrario, la gestión del patrimonio quedaría de todas formas en manos de un grupo elitista de personas, pasando a configurarse como participación ficticia. El mismo autor indica como estrategias útiles para fomentar una participación real, además de la educación popular como base fundamental, la realización de acciones-pretexto, es decir, de proyectos limitados, fáciles, vinculados a la vida cotidiana que son propuestos a voluntarios procedentes de la sociedad civil, con el fin de que se vuelvan conscientes de sus propias capacidades de acción y realización proyectual.

La participación de la comunidad debe caracterizar todas las fases de la proyectualidad ecomuseística, desde la inicial de investigación y determinación del capital cultural, hasta 
la de profundización y creación de un conocimiento compartido, desde la de interpretación y representación del patrimonio, hasta la de transmisión y restitución del mismo.

El grado de participación de una comunidad no es fácilmente definible. Para tal fin, en 1969, Sherry Arnstein elaboró una escala de la participación, en el intento de analizarla tanto desde el punto de vista cuantitativo como desde el punto de vista cualitativo. La clasificación propuesta va de una ausencia total de participación a una completa gestión proyectual por parte de los ciudadanos de la comunidad local (Arnstein, 1969). Dicha clasificación ha sido sucesivamente revisada y renovada, identificando tres distintos órdenes de implicación:

- $\quad$ La información, obtenida hoy día sobre todo a través de los portales Web.

- La comunicación y la comparación, efectuadas mediante el debate y la compartición de conocimiento, también mediados a menudo por herramientas tecnológicas.

- La participación activa, es decir, la intervención directa y concreta en los procesos de toma de decisiones.

Domenico Muscò (Muscò, 2007) identifica en la comunicación uno de los elementos básicos de la participación. Esta comunicación, además de interior de la comunidad participante, debe dirigirse asimismo al exterior para hacer posible que también los visitantes externos tengan la posibilidad de participar activamente, si bien de forma temporal, en un intercambio estimulante y enriquecedor, absolutamente no unívoco sino bidireccional. En este sentido, es bueno que la comunicación y, por tanto, también la participación, sean paritarias y simétricas. De hecho, nadie ocupa una posición que pueda definirse superior respecto a las demás: población, expertos llamados a colaborar, asociaciones locales, organismos administrativos y visitantes, desempeñan, cada uno, un papel singular y, por lo tanto, fundamental para el éxito de un ecomuseo.

Mediante la institución de un ecomuseo, pues, una comunidad consciente de su responsabilidad para con el patrimonio cultural se asume el compromiso de cuidar del territorio. El término "cuidado", originalmente asociado a la específica cualidad femenina identificada con la dedicación a los hijos y al otro por sí mismo en general, es entendido aquí en sentido heideggeriano, como un "cuidar de la vida". Cuidar del territorio significa ocuparse y preocuparse de su estado actual, de sus problemas, sus potencialidades, sus desarrollos futuros. Cada comunidad consciente del valor de su patrimonio cultural no puede descuidar su territorio. En efecto, el territorio no debe considerarse como un mero espacio físico, aunque las tendencias globalizadoras, homologantes y consumistas de los últimos decenios han fomentado a menudo una concepción de este tipo. El territorio es el ámbito en que se lleva a cabo la relación entre hombre y naturaleza, es el lugar donde se desarrollan los saberes, las tradiciones, las artes, los lenguajes, y todo ello pertenece a ese capital no tangible definido como patrimonio inmaterial (UNESCO, 2003). Pero esto no basta para definir su valor, ya que el territorio no es solamente el contexto en que se manifiestan estas muestras de civilización. Si por un lado el territorio influencia y modela a las sociedades que lo habitan y que lo han habitado en el tiempo, por otro también las comunidades actúan en el territorio, sobre todo a través de su representación e interpretación. El territorio, en cuanto lugar de referencia de la comunidad, de sus símbolos, sus valores, sus recursos, está investido de sentido y significados. Por consiguiente, es preciso volver a apropiarse del territorio entendido así, y de todos aquellos aspectos que, junto a él, han sido desvalorizados durante 
mucho tiempo: el paisaje (resultado de los procesos co-evolutivos de larga duración), la ciudad (lugar público de relaciones y civilización), el campo (lugar de antiguas tradiciones), los lugares abandonados (edificios en desuso, áreas deshabitadas, etc.).

A este respecto, precisamente el paisaje fue objeto del Convenio Europeo elaborado en el marco del Consejo de Europa y adoptado el 19 de julio de 2000 (Consejo de Europa, 2000). En dicho Convenio, en primer lugar, el paisaje es reconocido como bien colectivo que hay que proteger, gestionar y valorar en cuanto parte integrante del patrimonio cultural y natural de la humanidad. Se destaca además el papel que el paisaje desempeña en la definición de la identidad de las comunidades, así como en la calidad de vida de los ciudadanos. De ello se deriva que objeto de salvaguardia no deben ser solamente sitios y elementos excepcionales, sino el paisaje en su totalidad, constituido también por zonas ordinarias y relacionadas con la vida cotidiana de las poblaciones.

El cuidado del territorio es un deber, y al mismo tiempo un derecho, repartido entre todos los ciudadanos, quienes, a través de la participación comunitaria, pueden ofrecer su acción concreta: el mantenimiento de los agricultores, la custodia de los bosques de los guardas forestales, los comportamientos ecosostenibles de los turistas y de los habitantes, etc.

Sin embargo, en la base tiene que estar la que Alberto Magnaghi llama "conciencia de lugar", definida como "la concienciación, adquirida mediante una trayectoria de transformación cultural de los habitantes, del valor patrimonial de los bienes comunes territoriales (materiales y relacionales), en cuanto elementos esenciales para la reproducción de la vida individual y colectiva, biológica y cultural" (Magnaghi, 2010, p. 133). Gracias a ella, según Magnaghi, la recuperación del territorio histórico adquiere valor al ser capaz de hacerlo revivir como "territorio habitado" y no como mero contenedor de signos, objetos y recursos.

La "conciencia de lugar" se construye, en primer lugar, educando a los valores territoriales, materiales e inmateriales, entendidos como elementos reconocidos como punto fuerte o recurso sobre el que proyectar la propia vida y la de la comunidad. Sin embargo, es fundamental que la identidad territorial no desemboque en concepciones cristalizadas y radicales, intransigentes hacia cualquier forma de cambio y de evolución, de intercambio y de comparación. En efecto, el territorio "no es nunca un sistema aislado, cerrado, y sus relaciones sociales siempre están entrelazadas con contextos sociales, políticos, económicos y culturales extendidos a escalas diferentes" (Giorda, 2014, p. 66).

Por consiguiente, esto significa que el cuidado del territorio de que la población debería asumirse la responsabilidad, no se limita al propio ambiente vital, sino que, potencialmente, se extiende a áreas cada vez más amplias, hasta abarcar todo el planeta Tierra. El ecomuseo, si bien de forma limitada a la propia área, representa un proyecto innovador capaz de exaltar el territorio y de fomentar su cuidado.

\section{CONSTRUIR UN MAPA DE COMUNIDAD}

\subsection{LOS TIEMPOS Y LOS ESPACIOS}

Los mapas de comunidad expresan, pues, la interacción entre naturaleza y cultura a través de la lectura de las muchas historias que el territorio puede narrar. El proceso que lleva a la realización del mapa, conclusión de reflexiones individuales y colectivas y comunitarias, se articula en tres puntos (Maggi, 2008): 
- La diversidad, resultado de procesos que crean y procesos que nivelan las diferencias.

- El territorio, que se sustancia en "cosas y personas".

- $\quad$ La existencia en la continuidad.

Pero, ¿cuáles son las etapas fundamentales de la trayectoria de elaboración de un mapa de comunidad? Obviamente no es oportuno proponer una trayectoria válida a priori, en cualquier situación y para cualquier comunidad. Sin embargo, es posible identificar, a grandes rasgos, la que podría ser una secuencia de fases fundamentales:

- Definición de los objetivos y de las motivaciones del trabajo sobre el mapa.

- Encuentro preliminar de presentación de la iniciativa para aumentar la implicación de la comunidad local.

- Formación del grupo de trabajo, con la definición de subgrupos, en su caso, de los roles y de las personas encargadas de la facilitación.

- Identificación del área, del contexto y de las temáticas objeto del mapa.

- Búsqueda y recuperación de información sobre el objeto del mapa, incluso mediante formas de exploración no convencionales.

- Análisis de los resultados de investigación y debate, con el fin de crear un saber compartido.

- Elaboración del mapa o de los mapas con las técnicas consideradas más adecuadas.

- Restitución a la colectividad, mediante presentación del mapa y definición de los desarrollos futuros.

Es evidente que cada fase puede remitir a las anteriores, en un recorrido cíclico sin fin. Así, la restitución del mapa a la colectividad podría ser el punto de partida para la definición de nuevos objetivos, para la implicación de otros ciudadanos, para la propuesta de nuevas temáticas por desarrollar, y así sucesivamente.

El proceso de construcción de un mapa de comunidad no conlleva solamente un redescubrimiento del propio patrimonio local, sino también el redescubrimiento de aspectos y elementos de la cotidianidad, que a menudo descuidamos por negligencia y distracción. Se trata, por ejemplo, de la revalorización de tiempos extensos, de espacios inexplorados o abandonados, de relaciones auténticas entre personas incluso muy diferentes. Es indispensable que quien quiera participar en el trabajo sobre los mapas de comunidad y, en general, en el trabajo ecomuseístico, esté dispuesto a revisar y modificar sus propias creencias preconcebidas y sus modos de comportarse con relación a estos temas. El tiempo no será el frenético y rápido de los mil compromisos diarios, los espacios no serán los abarrotados, adornados y monumentalizados del pueblo o de la ciudad, las relaciones no serán aquellas fugaces, superficiales o impuestas por las convenciones sociales.

Los tiempos serán lentos, amplios, ricos de silencios y de momentos inertes. Un mapa de comunidad no se realiza en pocos días o en pocas semanas: se necesitan meses, si no años. En primer lugar, porque la zona y las temáticas por analizar son extensas y ricas de historia, de modo que resulta imposible agotar rápidamente el trabajo de conocimiento sobre ellas. En segundo lugar, porque la disponibilidad de los ciudadanos está limitada por los compromisos laborales y familiares, que dejan poco tiempo para el voluntariado. En tercer lugar, porque es preciso conceder tiempo a las personas para que puedan elaborar $\mathrm{e}$ 
interiorizar las ideas surgidas, reflexionar y atribuir significado a la iniciativa. Por último, porque durante la trayectoria pueden presentarse imprevistos, no necesariamente negativos, por lo que es necesario detenerse, o incluso volver a la fase anterior, para responder a las necesidades contingentes. Tiempos tan largos y lentos, si por un lado favorecen la recuperación de modalidades anticonformistas de pensamiento, por otro amenazan con aburrir y disminuir, si no anular, el interés de los participantes. Por consiguiente, es preciso que los gestores de la iniciativa, ya sean los facilitadores, los organismos administrativos o los ciudadanos más carismáticos, logren mantener alto el nivel de implicación y de acción de los participantes en el grupo de trabajo, mediante la propuesta de actividades apasionantes, de eventos y encuentros gratificantes (Muscò, 2007).

Los espacios, a veces, podrán ser oscuros, polvorientos, difícilmente alcanzables, angostos y desconocidos. Se trata de no-lugares, a estas alturas exentos de cualquier función productiva, social, cultural, pero ricos en memorias por evocar y recuperar, escondidas en viejos baúles olvidados, en los trasteros de antiguas moradas, entre las zarzas de bosques ya no explorados. También estos espacios, en virtud de su valor histórico-cultural, entran a formar parte de los mapas de comunidad y, en consecuencia, vuelven a ser realizados y conocidos por porciones cada vez más amplias de la población local. El mapa los interroga, poniendo de manifiesto lo que fueron, lo que son y en lo que podrán convertirse. El encuentro con estos lugares, la desorientación, el fuerte impacto perceptivo y emocional, el lento reconocimiento de sus significados más profundos, constituyen acciones de reterritorialización, gracias a las cuales el patrimonio local sigue viviendo.

Por último, las relaciones. Uno de los temas más debatidos de la contemporaneidad, donde la globalización, las nuevas tecnologías, los nuevos modelos individualistas de realización personal, parecen minar su naturaleza, o incluso su existencia. Esto, al menos, por lo que respecta a las relaciones no superficiales, las más profundas y significativas.

Trabajando en los mapas de comunidad, individuos distintos (por edad, sexo, estatus social, religión, etc.) han de colaborar para llegar a un fin común. Con el tiempo, este compromiso se convierte en ocasión de intercambio y de crecimiento personal, revelando todo el potencial ínsito en las relaciones más auténticas. En particular, ha surgido que el proceso de trazado de un mapa pone en juego las relaciones entre generaciones diferentes, portadoras de experiencias, memorias y valores totalmente disímiles, pero de todas formas capaces de dialogar (Pidello, 2004). Favorecer el desarrollo de relaciones interpersonales de calidad es tarea de quien, en el grupo, asume el papel de mediador o facilitador, a través de la propuesta de prácticas caracterizadas por la empatía, la lealtad, la aceptación, la escucha activa, la solidaridad y la cooperación.

Los mapas de comunidad, eligiendo oportunamente sus lenguajes, sus tiempos, sus espacios y sus modalidades de relación, para decirlo como Federico Luisetti, "pueden cambiar, aunque sea de forma imperceptible, la sociedad" (Luisetti, 2004, p. 55).

\subsection{CONOCIMIENTOS Y COMPETENCIAS INTERDISCIPLINARIOS: UN DIÁLOGO ENTRE LAS DISCIPLINAS}

Por todo lo dicho, resulta evidente que por las finalidades mismas de los mapas, estos entrelazan in primis saberes geográficos e históricos que se conectan con otros muchos saberes, yendo a constituir una trama de redes multidisciplinarias. Una trama compleja, a veces de difícil comprensión, pero precisamente por ello intrigante e interesante, 
atractiva y para nada trivial. Y las dificultades no están solo en el desciframiento de esta trama en el seno del ecomuseo por parte de quien se acerca al mismo, sino también en la construcción de la misma por parte de quien proyecta y gestiona el ecomuseo. Población, expertos, técnicos y administradores están llamados a colaborar y a poner a disposición del ecomuseo su saber, ya sea tradicional o especializado, teórico o práctico. Conocimientos urbanísticos, antropológicos, arqueológicos, botánicos, literarios, históricos, geográficos y así sucesivamente, pueden y deben concurrir en igual medida a construir la identidad del ecomuseo.

Los intentos de conexión entre historia y geografía son quizás los más antiguos y comunes: la historia se realiza siempre dentro de contextos territoriales, más o menos amplios, así como cada lugar es siempre poseedor de huellas del pasado. Sin embargo, muy a menudo también estos esfuerzos se revelan parciales, allí donde los aspectos históricos y geográficos simplemente son arrimados los unos a los otros, sin comprender los significados más profundos de su interconexión.

El destino del mapa de comunidad es, sin duda, el de evolucionar continuamente; de hecho, es un patrimonio en movimiento que propone la representación elaborada por la comunidad como herramienta de conocimiento de la cultura local.

Cada mapa debería encontrar ubicación dentro del ecomuseo o en archivo, y así convertirse en testigo de los cambios acaecidos en el territorio, en la comunidad y en su patrimonio cultural. Entonces, quien se dispone a leer un mapa de comunidad, se dispone a utilizar un instrumento que no solo es funcional a la orientación física típica del plano geográfico, sino que es capaz de favorecer una orientación más genérica y compleja, cultural y social, dentro de la comunidad local.

Antes que nada, el mapa desempeña su función principal de orientación para con la población misma. Todas las realizaciones elaboradas en el contexto del trabajo ecomuseístico pueden convertirse en patrimonio del pueblo de referencia, así como en útiles dispositivos para la gestión y planificación de la vida comunitaria.

En esta perspectiva, el mapa puede ser utilizado para el análisis del territorio destinado a la proyectación urbanística, a la enseñanza de la geografía, al desarrollo agrícola, al turismo sostenible, a la educación ambiental, y así sucesivamente. De esta manera, en cierto sentido, toda la comunidad podría estar involucrada en las decisiones relativas a estos ámbitos, ya que estas se basarían en las evaluaciones y en los resultados surgidos del trabajo ecomuseístico. Sin embargo, se trata de una idea de gestión del territorio todavía muy poco compartida y difícil de realizar. Tal y como sostienen algunos autores, si bien los mapas de comunidad son documentos participados, estos "no constituyen herramientas adecuadas para la aplicación de las lógicas de gobierno participado" (Donato, 2010, p. 216).

En segundo lugar, el mapa de comunidad desempeña una función de orientación para con los foráneos, aquellos que visitan el territorio como turistas o se establecen en él durante un periodo más o menos largo.

No tomar en consideración a los turistas como importantes usuarios del mapa, precisamente como considerarlos los principales y más importantes, representa un grave error de valoración. El ecomuseo, de hecho, es lugar de intercambios, interconexiones, contaminaciones, entre sus habitantes y los visitantes. Por un lado, mediante el mapa los turistas entran en contacto con los aspectos más relevantes de la cultura local, profundizan su conocimiento, lo interiorizan. El territorio tiene así la posibilidad de narrarse, de expresarse y darse a conocer en ámbitos cada vez más amplios. Por otro lado, la comunidad tiene 
la posibilidad de acoger a otras civilizaciones, de obtener de ellas elementos culturales interesantes, sin renunciar a aclarar cuáles son sus elementos identitarios.

Es indispensable que, ya en fase de proyectación, el grupo de trabajo adopte medidas encaminadas a satisfacer las necesidades de todos los posibles usuarios del mapa. En esta perspectiva, el mapa de comunidad, para ser eficaz, debe estar caracterizado por criterios de claridad, sencillez y exhaustividad: un mapa a medida de todos y cada uno, capaz de ser estimulante y comprensible para cualquiera que desee utilizarlo. Una de las medidas más sencillas por adoptar puede ser la inserción de uno o varios textos al pie, de una leyenda o de otros elementos explicativos. Además de esto, el uso razonado de los colores, las fotografías, las perspectivas, las escalas de tamaño y los topónimos constituyen útiles ardides. En cambio, hay que evitar las reducciones excesivas de las dimensiones, así como la concentración exagerada de elementos en un mismo punto. La comunicación y las formas que esta asume pueden convertirse, pues, en las principales fuentes de éxito o fracaso de un mapa de comunidad.

Por último, han de incluirse entre los destinatarios de los mapas de comunidad también las generaciones futuras. Como si fueran turistas en pos del descubrimiento del territorio, los nuevos pertenecientes a la comunidad local se encuentran inmersos en una cultura que han de conocer y comprender, para luego hacerse garantes de la misma. También, y sobre todo, para ellos los mapas de comunidad deben ser conservados como valiosos tesoros.

\section{ECOMUSEOS Y MAPAS DE COMUNIDAD. EL CASO DE ITALIA}

Las ideas innovadoras introducidas por el movimiento cultural de la nueva museología, descendiente de los padres fundadores De Varine y Rivière se referían, en concreto, a

- La revalorización de los aspectos ordinarios y vinculados a la cotidianidad de la vida comunitaria, superando la reducción de la cultura popular solo a los aspectos curiosos e insólitos.

- La superación de la visión idílica de los contextos rurales como únicos poseedores de tradiciones y la mayor atención a los contextos urbanos e industriales.

- La experimentación y la introducción de formas de participación directa de los visitantes.

- La valorización de la conservación in situ, es decir, en los contextos de origen, y el consiguiente descrédito de la conservación ex situ, es decir, fuera de la sede originaria.

En Italia, Fredi Drugman es considerado el principal divulgador de las ideas ligadas al movimiento de la nueva museología, elaboradas en el transcurso del siglo XX y ahora en vías de difusión y aplicación. Drugman propone una revisión de la museología capaz de competir con la complejidad de la sociedad contemporánea, de proporcionar las bases para la identidad cultural de los pueblos superando las dificultades vinculadas a la rapidez con que se suceden innovaciones, modas y tendencias. Utilizando dos metáforas elocuentes, Drugman desvela lo que considera el secreto para alcanzar semejante meta: “... transformar el museo de "salón de las Musas" a Ágora, lugar público por excelencia, punto de agregación de los ciudadanos, casa del colectivo” (Bonacchi, n.d.). 
La aplicación de las indicaciones innovadoras propuestas por la nueva corriente museológica no fue sencilla y exenta de problemas, tanto cuando se trataba de nuevas propuestas museísticas, como cuando se trataba de viejos museos renovados. En primer lugar, porque la recuperación de testimonios, materiales o inmateriales, de la vida de hombres y mujeres comunes, no siempre es fácil, si no imposible: trajes, instrumentos de trabajo, herramientas, juguetes y demás objetos tradicionales, al ser considerados exentos de valor, eran relegados a viejos trasteros, o peor, tirados como residuos. En segundo lugar, porque toda la proyectación del ecomuseo requiere la participación y la colaboración de los ciudadanos, a menudo ocupados con un trabajo a tiempo completo y poco disponibles al voluntariado. Por último, porque las dos condiciones anteriores conllevan un horizonte de tiempos largos, a veces afanosos, de colaboraciones difíciles, de carencias a la hora de lograr recursos (económicos y humanos).

El de la nueva museología se puede definir como un éxito todavía parcial. Si bien es cierto que la necesidad de promover los territorios y las identidades locales conectadas a los mismos es hoy más sentida que en el pasado, también es verdad que la gran variedad de experiencias museísticas innovadoras ha creado muchas situaciones indefinidas y un desorden general. Junto con las iniciativas realmente ecomuseísticas, hoy día se pueden encontrar ecomuseos que no son realmente tales (y que deberían ser denominados de otra manera, por ejemplo, "museos al aire libre", "museos de sociedad", etc.), y museos que, aun no teniendo la denominación de ecomuseo, se configuran como tales.

Las experiencias de los ecomuseos llegaron a Italia con un retraso considerable, que puede atribuirse a las características y a la historia del país. Antes que nada, el logro de la unidad nacional, si bien formalmente realizado, se reveló un proceso aun no concluido y de difícil realización en el plano práctico: las diversidades regionales eran muy acentuadas, y en parte lo siguen siendo. La tendencia de los gobiernos fue la de adoptar políticas culturales de desvalorización, si no de negación, de las diversidades presentes en el territorio. En consecuencia, se pusieron en práctica procesos de centralización de los patrimonios locales, en un intento de crear una sensación de identidad nacional. Entre los resultados de estas tendencias hay que recordar la creación de numerosos museos del Resurgimiento y de Historia Patria, museos creados a finales del siglo XIX a partir de iniciativas políticas que aspiraban a la recuperación de la memoria histórica y de la identidad de la nación. Estos museos, dedicados al recuerdo de héroes nacionales, a las batallas por la independencia, a objetos símbolo de la recién nacida identidad nacional, a pesar de la diversidad de las finalidades, pueden ser considerados precursores de los nuevos modelos museísticos.

La propuesta de iniciativas innovadoras partió precisamente de la conversión de las finalidades: de la creación de una identidad nacional, a la valorización de las identidades locales y de la diferencia como riqueza por preservar. No obstante, la mayor parte de las experiencias puestas en marcha en el territorio poseen una definición diferente de la de ecomuseo, aun compartiendo con él la tendencia a extender el área de interés más allá de la tradición museística. Queriendo analizar la evolución histórica de estas instituciones innovadoras, surge un cuadro caracterizado por la presencia de cuatro tipos predominantes de museo (IRES Piemonte, 2000):

- El museo-colección, formado por objetos tradicionales, de uso común, que adquieren valor de patrimonio gracias a su vínculo con la historia pasada del territorio. A menudo debe su fundación a la acción de grupos locales o de 
individuos a quienes pertenecen las recopilaciones de los objetos expuestos (un ejemplo es la colección Guatelli en Ozzano Taro-Emilia Romaña).

- El museo de cultura material y oficios, donde se valorizan las actividades tradicionales (agricultura, artesanía local, etc.) o típicas (producción del vidrio, hilatura de alfombras, etc.), a menudo a través de la recuperación de edificios productivos (molinos, carpinterías, etc.). Sin embargo, los aspectos laborales representan únicamente en parte la comunidad local y limitan la atención a temas específicos (constituyen un ejemplo de ello el Museo del Vino de Todi (Umbría) y el Museo del Olivo de Imperia-Liguria).

- El museo del ambiente, que centra su atención en los aspectos geográficos y ecológicos del territorio, partiendo a menudo de la recuperación de yacimientos arqueológicos (constituye un ejemplo el Ecomuseo de la Maiella occidental en Abruzos). A pesar de todo, la valorización del territorio no está acompañada de un interés por los aspectos sociales vinculados al mismo.

- El museo de las gentes, que representa la vida rural de las comunidades, interesándose por la realidad cotidiana, los comportamientos y los estilos de vida. Recurre frecuentemente a la reconstrucción de ambientes (constituye un ejemplo el Museo delle Genti trentine de San Michele all'Adige, en Trentino Alto Adigio.

$\mathrm{Si}$, por un lado, la multiplicidad de modelos coexistentes ha llevado a la difícil transposición de las nuevas indicaciones ecomuseísticas, por otro ha sido la base de la reinterpretación de algunos museos preexistentes en sentido ecomuseístico.

A partir de los años noventa, los ecomuseos se fueron difundiendo en mayor medida tras la intervención de los organismos de gobierno local en el centro-norte y de los parques naturales en el centro-sur, como una de las formas más innovadoras del proceso participativo de ciudadanía activa.

Actualmente, la mayor presencia de museos se registra en Piamonte, en el noreste y en el centro de Italia (entre los Alpes Marítimos y los Apeninos toscanos), mientras que el fenómeno está mucho menos difundido en el centro y sur del país. Además de esto, Maggi observa la presencia de diferencias significativas también en la tipología de las propuestas ecomuseísticas: en el centro-norte se fomenta la identidad territorial de áreas más bien amplias o coordinadas, mientras que en el centro-sur la atención se fija en áreas geográficamente limitadas valorizando los aspectos medioambientales y de tradición local.

Hoy día, esta variedad de propuestas y de identidades locales ha conseguido consolidarse como característica de Italia, capaz de atraer, de enriquecer la oferta, de valorizar el patrimonio de la nación.

Cada ecomuseo, adoptando un modelo que hace de la participación un elemento constitutivo de su identidad, debe dotarse de instrumentos que la estimulen y la faciliten, instrumentos capaces de convertir a los ciudadanos en protagonistas activos en la experiencia de salvaguardia de su propio patrimonio.

Uno de los dispositivos que se ha distinguido en los últimos años como particularmente eficaz es el de los "mapas de comunidad", mapas singulares inspirados en el fenómeno de los "Parish Maps", introducido en Inglaterra a comienzos de los años 80 y posteriormente difundido y experimentado en otros países. Los mapas de comunidad, en las distintas formas en que han sido elaborados como los parish maps, los mapas culturales, los mapas perceptivos, los mapas interpretados o filmados, hacen de la participación una característica esencial. 
Los mapas de comunidad surgen en Inglaterra en los años ochenta en el seno de la asociación sin ánimo de lucro "Commond Ground", fundada en 1982 por Sue Clifford, Angela King y Roger Deakin. Entre las finalidades de la asociación, desde su fundación, está el conocimiento y la valorización del patrimonio local a través de la implicación activa de las comunidades locales. Esta intención, que podríamos resumir y profundizar aún más en el concepto de "public history" -que afrontaremos en el apartado siguiente-, llevó a la realización de los Parish Maps, los mapas de comunidad, que constituyen una respuesta al proceso de homologación de los lugares y de las culturas locales a modelos que tienden a anular las diferencias en favor de un cierto globalismo.

El término Parish significa literalmente "parroquia" y deriva de una distribución administrativa de tipo eclesiástico, y era utilizado con el significado de "pequeña comunidad". En Italia podría corresponder a un "pequeño municipio" o a una "aldea", traducido generalmente con el término de comunidad (Clifford, Maggi \& Murtas, 2006, p. 1).

La denominación tiene su origen en el significado asumido por la circunscripción de la parroquia eclesiástica (Clifford, Maggi \& Murtas, 2006, p. 4), entendida como medición del paisaje inglés desde los tiempos de los Anglos y los Sajones. La jurisdicción civil de la "parroquia" aparece en los años noventa del siglo XIX como el más pequeño espacio en que se ejerce la democracia. Los galeses expresan la dimensión local con el término y filltir sgwar, bro and cynefin (en casa, sobre la tierra madre y en el territorio) y en alemán Heimat (patria chica o patria local) contiene los mismos significados.

Por consiguiente, la asociación Common Ground ha propuesto la palabra "Parish" en esta acepción del territorio: una pequeña comunidad integrada en una relación entre hombre y naturaleza capaz de producir una específica cultura e identidad. Los tiempos han llevado a una redefinición administrativa de los confines territoriales, que ya no representan los de las comunidades, y de su sentido de pertenencia, del que en la mayor parte de los casos se prescinde.

Entre lugares y personas se pueden crear alianzas fuertes, en las que naturaleza, identidad y lugares juegan un papel profundo.

Para Sue Clifford, el paisaje cultural es una creación del hombre respaldada por la naturaleza, es tanto una cosa física como una red invisible. Hugues de Varine expresa un punto de vista cercano al adoptado por la asociación inglesa y por sus miembros, entendiendo el patrimonio cultural como capital común, por tanto

capital cultural, estrechamente ligado a nuestras culturas vivas, o sea valores, al lenguaje, a la historia, al entorno cotidiano, al clima, a las creencias, a los modos de vida. Es lo que los ecomuseos italianos llaman cada vez más a menudo "el paisaje", haciendo referencia al relativo Convenio europeo. (De Varine, 2010, p. 2).

Una visión que explica aún más la significativa relación entre las finalidades del ecomuseo y los mapas de comunidad.

Common Ground, con el fin de apoyar a las comunidades locales en la determinación y apreciación de su patrimonio, define los principios de la Local Distinctiveness. Con el término local se hace, pues, referencia al entramado de relaciones entre personas y territorio

\footnotetext{
La parroquia civil no coincide con la eclesiástica y es la menor unidad del gobierno local en Inglaterra. Desde 1994, Inglaterra está dividida en nueve regiones (a su vez divididas en condados y distritos).
} 
que generan sentimientos de pertenencia, con el de distinctiveness a las peculiaridades de cada territorio en sus aspectos antrópicos y naturales. Estos principios orientan las acciones de aquellos que se reconocen en el espíritu de la asociación.

Local puede ser la parroquia, pero también el barrio, la localidad, la calle principal, la aldea, el burgo, el área a que las personas sienten que pertenecen, y que les concierne a través de la familiaridad de la costumbre. La dimensión del espacio considerado es importante; cuanto más grande es el territorio, menor es la sensibilidad para con el mismo. Una vez más no cuentan los confines administrativos, que permanecen conceptos definidos desde el exterior y abstractos, sino los personales, definidos desde el interior y motivados por una base cultural y natural.

Pequeño no debe ser confundido con simple, en su interior están presentes complejidad y desorden que, sin embargo, logran encontrar un sentido de unidad capaz de integrar las partes. Carácter distintivo local es también no separar los puntos de vista y reconocer en cambio su sinergia.

El carácter distintivo de un lugar, elemento fundamental en la "filosofía" de la asociación Common Ground, presenta varios aspectos. El carácter distintivo de un territorio no viene dado por la diversidad en sí, ya que es una dimensión que incluye todos los elementos que entran en juego en un paisaje: la gente, los lugares y los símbolos compartidos por la comunidad. Pero las definiciones de los caracteres distintivos deben surgir desde dentro de la comunidad hacia fuera y admitir la presencia de una complejidad interna y de falta de homogeneidad.

El carácter distintivo de un lugar puede abarcar diferentes aspectos: los detalles, las particularidades, la pátina del tiempo, la autenticidad. Todas ellas cualidades de lo cotidiano no sencillas de comunicar porque implican una dimensión afectiva que escapa a rígidas categorías y a fáciles lecturas.

El detalle como rasgo específico de un territorio reviste cierta importancia para la vida de la comunidad: la pérdida de un árbol singular, un cambio en la escena local, pueden producir una sensación de extravío. Los individuos reconocen el lugar donde se encuentran por una serie de indicios familiares. Dondequiera que uno se encuentre, son los detalles y las superposiciones los que otorgan a ese lugar su carácter específico.

La particularidad puede ser a su vez una tipicidad y puede consistir en el elemento insólito, especial, extraño, idiosincrásico. El elemento raro puede sin duda ser un factor importante para dar a un lugar un sentido de sí, pero al mismo tiempo hay que procurar que no se convierta en un vínculo. Es la comunidad la que define su identidad: puede ser un característico modo de construir las paredes, un determinado tipo de plantas, una cierta tradición gastronómica; el quid no está tanto en la diferencia, sino en lo que es capaz de expresar adecuadamente un territorio.

La pátina del tiempo indica los signos dejados en el territorio por las distintas sociedades que se han ido sucediendo, huellas que no deberían ser eliminadas, no tanto con la intención de querer detener el tiempo, sino con la de querer dar paso al encuentro con las presencias que pueblan los lugares.

Sería deshonesto e irreal presentar una visión unidimensional de un territorio, tanto por lo que respecta a los habitantes como a los posibles visitantes externos.

El carácter distintivo local no viene dado por la belleza, sino por su autenticidad, porque lo real y lo verdadero poseen una fuerza y un significado para aquellos que se miden con esa dimensión. Por eso tiene sentido dejar espacio a paredes desconchadas, para poder leer el antes y el después y permitir así el acceso a la vida del lugar. 
Dondequiera que uno se encuentre, son los detalles y las superposiciones que tienen un significado tanto para el individuo como para la comunidad los que dan a aquel lugar su carácter peculiar. Por consiguiente, la acción de la asociación Common Ground está dirigida a salvar esta idea de distinción local, ofreciendo una respuesta al proceso de homogeneización y empobrecimiento de las riquezas del territorio.

Las fuerzas que tienden a la homogeneización de los paisajes, les privan tanto de las cosas visibles como de las invisibles que tienen un significado para la comunidad, desvalorizan la sabiduría que se ha desarrollado en el tiempo, y borran los fragmentos desde donde partir para aunar la historia de la naturaleza con la del hombre.

Sue Clifford expresa el sentido de lugar:

Cada lugar se encuentra en alguna parte. Cada lugar (y cada persona) es el museo viviente de sí mismo, donde las historias, ya no lineales, codean en el mismo escenario como astillas de innumerables épocas que se acumulan capa sobre capa, signo sobre signo, fragmento sobre fragmento, construyendo una riqueza que, en el momento en que es reconocida, puede ser leída. (De Varine, 2010, p. 7).

El empobrecimiento de la idea de lugar dictado por una pérdida de conocimiento del territorio próximo va de la mano con una ampliación de adquisición de datos, y por tanto de una pluralidad de fuentes, presentes en el planeta, ya que el "globalismo" es

una tendencia imparable ligada a las nuevas dimensiones del planeta y al rápido desarrollo de las comunicaciones y de la tecnología que han acercado países distintos y lejanos en un sistema unitario, aunque no uniforme. Un nuevo orden global, una verdadera edad global transforman los hechos locales en hechos planetarios, disuelven un poco por vez las pequeñas unidades nacionales dentro de organismos de alcance internacional, rompen con las tradiciones locales a favor de modos de vida más uniformes. (Barbieri, Canigiani \& Cassi, 2003, p. 112).

Sin embargo, romper con las tradiciones locales y crear una fractura con el propio pasado cambia profundamente el escenario vital de las personas. Produce el enrarecimiento y la disgregación del tejido social, creando pérdida de sentido de los lugares y de las personas.

Los mapas pueden convertirse en una herramienta de protección de la especificidad del patrimonio cultural, entendido en su última acepción más amplia, asimismo pueden intentar recomponer esa disgregación y pérdida de sentido colectivo que en las últimas décadas ha arrollado a las comunidades.

Common Ground, en el intento de devolver el sentido de la memoria a los lugares, lanzó en los años ochenta el ya citado proyecto Parish Maps. En 1884, en Dymock, en el Gloucestershire, se realiza un primer mapa en formato A1. En la década siguiente el método se extiende también gracias a la acción de la Countryside $\mathrm{Agency}^{2}$, que lo adopta como práctica útil para la protección del territorio. Los mapas realizados en el Reino Unido a caballo del milenio son más de dos mil (Clifford, Maggi \& Murtas, 2006) y muchas son las comunidades que elaboran los propios ${ }^{3}$.

La Countryside Agency es una agencia nacional inglesa que se ocupa del mundo rural en sus distintos aspectos, parques y patrimonio local.

El sitio web de la asociación Common Ground (www.commonground.org.uk) actualiza la lista en función de la información 
En el año 2000, la administración del West Sussex County, para celebrar el Milenio del West Sussex, ${ }^{4}$ comienza el proyecto "Parish Maps". Los mapas son considerados un medio eficaz para documentar el singular momento histórico. La iniciativa involucra a numerosos grupos locales y en el ámbito del proyecto se elaboran 66 mapas que fueron expuestos en el Worthing Museum and Art Gallery hasta febrero de 2002, mostrando una gran variedad capaz de revelar mucho sobre los lugares representados. Los mapas han sido producidos como pósteres y puestos a la venta. Casi todos los mapas originales son conservados en los lugares de referencia y en espacios de frecuentación pública; cuando las comunidades eran tan pequeñas que no tenían espacios adecuados para la exposición, eran confiados a una persona que colaboraba en el proyecto en el ámbito local.

En el marco de sus numerosos proyectos, la asociación dio vida también a una iniciativa denominada England in particular (Clifford \& King, 2006), gran enciclopedia de las "peculiaridades territoriales", publicada en 2006. La iniciativa recogió material informativo y experiencias destinadas a respaldar a las comunidades locales en la difusión de sus conocimientos y del respectivo patrimonio cultural.

Common Ground ha centrado su acción en el carácter de la "distinción local" y en los procesos de desarrollo sostenible de los territorios y de sus comunidades a través de la recuperación de los saberes ínsitos en su interior creyendo que «Orgullo, motivación y sentido de comunidad tienen mucho que ver con la identidad y la continuidad de la historia» (Clifford, Maggi \& Murtas, 2006, p. 8). Esto conlleva una visión del territorio dictada por la relación entre lugares y personas, relación que puede tener que ver con el elemento extraordinario, pero pone su atención sobre todo en lo cotidiano.

\subsection{ALGUNOS EJEMPLOS DE MAPAS}

Nos resulta claro que los mapas son mucho más que una representación cartográfica, ya que expresan la idea del lugar, resumen la visión del mundo de aquellos que lo habitan y al mismo tiempo localizan los símbolos del territorio y los confines naturales dentro de los que la comunidad se reconoce.

Para sintetizar, como recuerda Kim Leslie (Castellari, n.d.), directora del "West Sussex Parish Map Project", la producción y la realización de un mapa implica una representación de una visión del mundo local desde abajo, cuyo proceso implica la liberación de energía y de crecimiento educativo.

Y es precisamente en este punto que quisiéramos fijar ahora la atención. ¿Cuál es la conexión con la enseñanza de la historia? Tras haber definido la herramienta "mapa de comunidad", ¿puede tener alguna utilidad en el aprendizaje de la historia? La respuesta nos parece evidente. Sí, la construcción de un mapa de comunidad que arranque desde el contexto escolar, compartida por la comunidad, puede ser un excelente ejemplo de ejercicio a la ciudadanía activa.

Al ser el mapa de comunidad una idea más bien reciente y por tanto poco conocida, para quien oye hablar de él por primera vez o bien desde hace poco tiempo, es difícil hacerse una

\section{llegada.}

$4 \quad$ El Sussex es un condado histórico del sur de Inglaterra, dividida por fines administrativos en los dos condados de West Sussex y East Sussex. La responsable del proyecto de los "Parish Maps" para el West Sussex ha sido Kim Leslie. 
idea de cuál puede ser el resultado en concreto. Por consiguiente, entrar en contacto con otras y variadas experiencias de mapas de comunidad puede ser de gran ayuda.

Las experiencias de trazado de un mapa que figuran a continuación ${ }^{5}$ quieren servir de ejemplo de lo que es el trabajo y el producto de las comunidades ecomuseísticas. Cada uno de los trazados ha sido elaborado a partir del propio contexto determinado, de modo que ninguno puede servir de modelo estándar para otras realizaciones. Cada uno de ellos está indudablemente convalidado, puesto que cumple con los criterios adoptados por la comunidad misma para representarse.

Figura 2. Mapa de comunidad de Raggiolo ${ }^{6}$

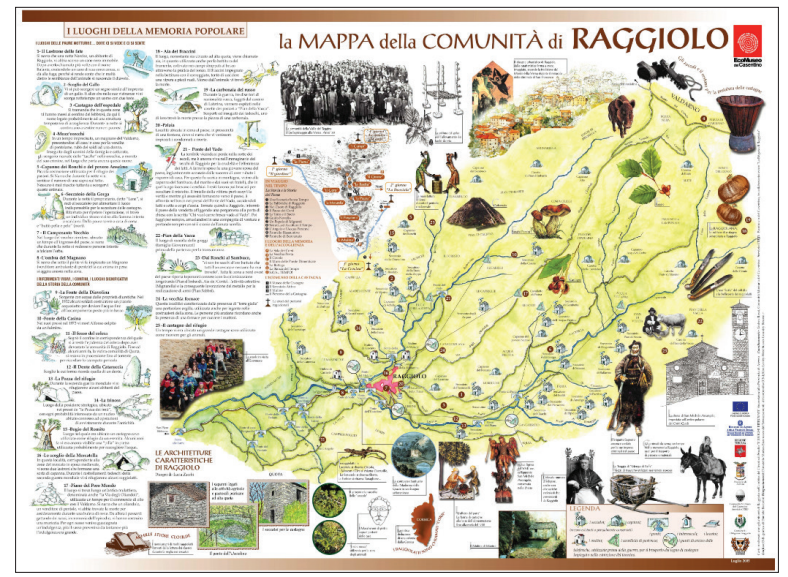

El proyecto de comunidad de Ortignano Raggiolo (Arezzo) comenzó en 2004 y concluyó en el verano de 2005. Promovido por la Comunidad de Montaña del Casentino de concierto con la Administración Municipal de la localidad y con la contribución de la asociación La Brigata di Raggiolo, el trabajo sobre el mapa de comunidad involucró a grupos de unas 15 personas en el periodo invernal, cuando los residentes ascienden a solo 80 personas, y a grupos más consistentes, de 30-40 personas, en el periodo estival, cuando regresan algunos paisanos y muchos turistas visitan el territorio. En los grupos de trabajo participaron en su mayoría personas ancianas, que constituyen buena parte de la población residente. Por este motivo, el mapa está caracterizado por una orientación al pasado, más que al presente y al futuro.

El mapa fue realizado sobre la base de referencias extraídas de la cartografía oficial y enriquecido mediante la colocación en el mismo de lugares de la memoria popular y de

\footnotetext{
$5 \quad$ Los ejemplos de mapa de comunidad presentados no quieren ser propuestos como (o en cuanto) cualitativamente mejores que otros. Aunque se han desarrollado desde hace poco como movimiento, en Italia se puede localizar un discreto número de mapas de comunidad, si bien muy limitado en comparación con la gran cantidad de identidades territoriales presentes. Por este motivo, es necesario optar por algunas iniciativas y proponer solo las que sirvan de ejemplo de mapa.

6 Sitio web de referencia: http://www.mappadicomunita.it/mdc/wp-content/uploads/2009/02/mappa_raggiolo.pdf
} 
arquitecturas características. Al resultado final, repleto de leyendas y recuadros temáticos, contribuyeron también algunos jóvenes autores de dibujos.

Figura 3. Mapa de comunidad de Campotto ${ }^{7}$

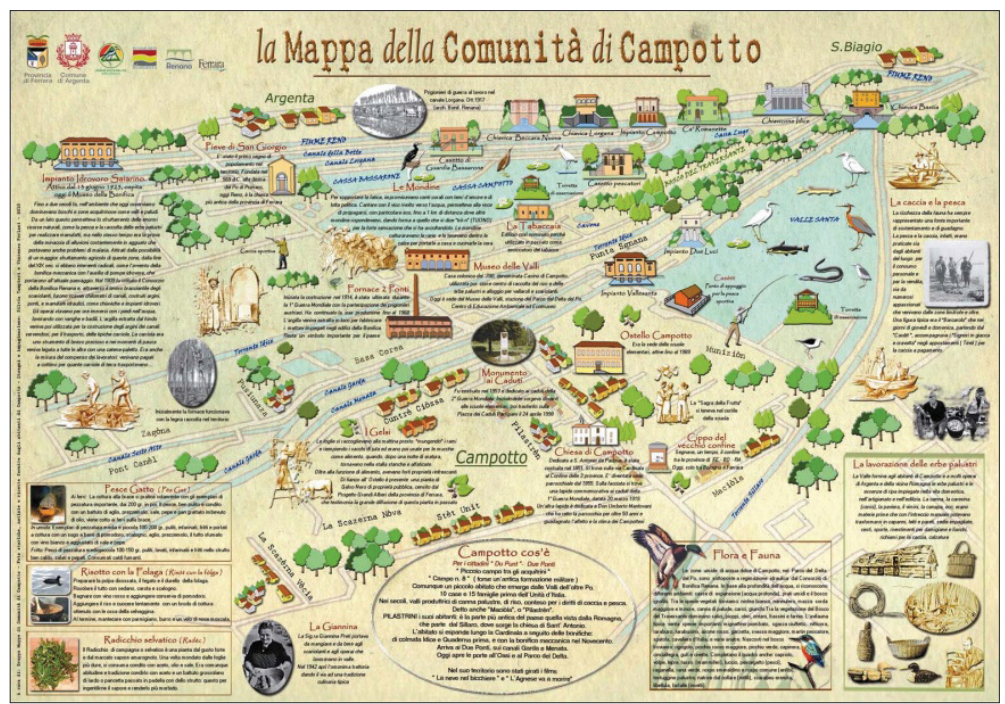

El proyecto ecomuseístico sobre el mapa de comunidad de Campotto de Argenta (Ferrara), promovido por la provincia de Ferrara y por el Ayuntamiento de Argenta, comenzó en enero de 2008 y concluyó en enero de 2011. La comunidad, predominantemente anciana, mostró una desconfianza inicial hacia esta nueva forma de participación, que fue superada gracias al conocimiento gradual de los coordinadores del proyecto y a la creación de grupos temáticos de trabajo.

La atención se dirigió principalmente a la recopilación de fotos que daban testimonio de la memoria de la localidad, a la cocina y las recetas típicas, a los topónimos, la onomástica geográfica y la cartografía, a las maneras de actuar, las canciones y las cantilenas. De esta manera se identificaron los principales elementos identitarios a insertar en el mapa: la pesca y la caza, el trabajo en el valle y las mondadoras de arroz, el trabajo en los campos y las ocupaciones comerciales, las actividades deportivas, las fiestas y eventos, las familias, los grupos de personas, los paisajes.

La restitución del mapa encontró el favor de los residentes, tanto es así que el trabajo continuó con la creación de una exposición, "Campotto si racconta" (Campotto habla de sí), en septiembre de 2011.

Sitios web de referencia: https://ecomuseodallememoriealfuturo.files.wordpress.com/2013/02/mappa-campotto.jpg y http://ibc.regione.emilia-romagna.it/argomenti/rete-ecomuseale/allegati-rete-ecomuseale/5_Giuliana-Castellari_-Mappedi-Comunita.pdf 
Figura 4. Mapa de comunidad de Acquarica di Lecce ${ }^{8}$

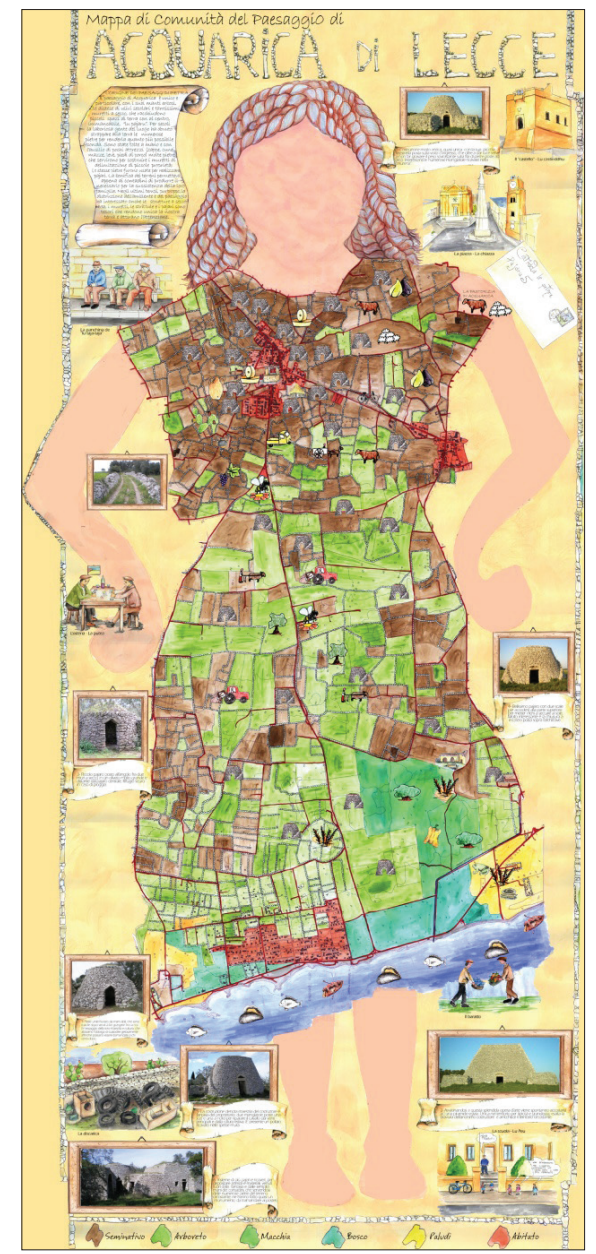

El trabajo para la creación del mapa de comunidad de Acquarica di Lecce, desarrollado como taller del Ecomuseo de los paisajes de piedra, comenzó en noviembre de 2007 y se prolongó durante un año aproximadamente. Contó con la participación de una decena de personas, especialmente interesadas en la salvaguardia del patrimonio local. Tras una serie de encuentros y a través de una entrevista individual a cada participante, surgieron los elementos identitarios prioritarios que salvaguardar. En primer lugar, el aspecto típico del territorio, el de los paisajes de piedra. A continuación, las características locales vinculadas al cultivo de los campos, a las arquitecturas rurales, a los oficios relacionados con la ganadería y la pesca.

Sitio web de referencia: http://www.ecomuseipuglia.net/ecoPuglia.php 
La definición de los confines territoriales por representar en el mapa puso de manifiesto que la percepción de los ciudadanos iba mucho más allá de los confines administrativos de la población. El mapa asumió la forma de una joven mujer vestida de campos cultivados, pantanos, zonas costeras y centros habitados, "cosidos" juntos por carreteras asfaltadas representadas en rojo y muros de piedra en seco representados en blanco. Estos últimos, tradicionalmente utilizados en los campos para la división de los terrenos, fueron empleados también para enmarcar el mapa y para crear el título. También el pergamino situado en la zona superior izquierda está dedicado a este aspecto del territorio, describiendo su nacimiento y su historia.

Sobre el mapa se colocaron los contenidos surgidos como más relevantes, a través de iconos que remiten a los textos y a las fotografías situados a los lados de la mujer: flora y fauna, cultivos y transformación de los mismos, monumentos, yacimientos arqueológicos, economía y estilos de vida. La ubicación misma de sus representaciones siguió criterios específicos: a la derecha, los textos que aclaran la percepción del territorio por parte de la población; a la izquierda, las temáticas relativas a la historia agrícola y a la economía. Por último, la ilustradora trabajó sobre estas indicaciones estructurales y de contenidos y, utilizando la técnica de la acuarela, creó la representación del territorio y de su patrimonio cultural.

\section{HACER HISTORIA LOCAL CONSTRUYENDO MAPAS DE COMUNIDAD. NUEVAS PRÁCTICAS DE EDUCACIÓN AL PATRIMONIO}

En Italia, el uso didáctico de los mapas de comunidad para la enseñanza y el aprendizaje de la historia fue introducido por el ya citado "Centro Internazionale di Didattica della Storia e del Patrimonio" (Centro Internacional de Enseñanza de la Historia y del Patrimonio - DiPast) con interesantes experimentaciones en las escuelas primarias y secundarias obligatorias en la óptica de un currículo vertical de las competencias ${ }^{9}$.

Uno de los momentos fundamentales en la proyectación de los mapas de comunidad es el de la profundización de los conocimientos relativos al propio territorio, para poder llegar, al final, a la construcción de un saber comunitario compartido. Dicho momento debe principalmente su particularidad a las metodologías, para nada tradicionales, que despliega.

En este sentido, habría que distinguir las modalidades exploratorias, destinadas a identificar las peculiaridades del patrimonio local, de las modalidades de investigación, encaminadas a la obtención de información sobre las temáticas específicas.

La palabra "exploración", en su significado más auténtico, remite al intento de descubrir lo que está oculto o es desconocido aún, a través de los más diversos medios útiles.

En el sentido común, sin embargo, el término ha sido asociado cada vez más a formas de orientación convencionales: el uso del plano geográfico, el desplazarse siguiendo las indicaciones de unos letreros fijos, el adentrarse hacia senderos bien definidos. Si esto responde, evidentemente, a la necesidad humana de seguridad y de puntos de referencia, también es cierto que este modo de proceder limita mucho el acto exploratorio, no solo reduciendo las posibilidades de descubrimiento, sino también atenuando el carácter aventurero de la experiencia.

\footnotetext{
Las primeras experimentaciones fueron puestas en marcha durante el año lectivo 2013/2014 en el distrito escolar de Conselice (Rávena).
} 
Tal y como afirma el sociólogo Davide Bazzini, es preciso "caminar, volver a adueñarse de la fatiga y del tiempo, de la percepción y de la observación” (Bazzini, 2004, p. 17). Él, como modalidad de facilitación para el trazado de un mapa del territorio, propone lo que llama "walking”, es decir, la revolucionaria (al menos en nuestros días) acción de caminar o pedalear lentamente, sin una meta, en pos de descubrir los lugares y las comunidades. El autor llega incluso a exhortar a la abolición de las visitas guiadas con guía, de los letreros y de los folletos descriptivos a los que normalmente se remite el conocimiento de un territorio (Bazzini, 2004).

Hugues de Varine, igualmente, indica que recorrer a pie un territorio, encomendándose a los habitantes como guías y narradores de su patrimonio cultural, constituye una válida herramienta de exploración.

Si bien la exploración nunca puede considerarse concluida definitivamente, al final de esta fase se habrán identificado los objetos, materiales e inmateriales, sobre los que trabajar, antes que nada a través de una actividad de investigación que profundice su conocimiento.

También la actividad de investigación a menudo es confinada en ámbitos particulares (laboratorios, yacimientos arqueológicos, etc.) y en personas específicas (los investigadores, los científicos, etc.). En cambio, en el contexto de los mapas de comunidad, la investigación involucra a todos aquellos que deseen participar, y se aplica a todos los objetos de interés, dondequiera que se encuentren. Además, también esta fase se caracteriza por las singulares metodologías que adopta.

Cada comunidad elige las estrategias de indagación que mejor se adaptan al contexto. Habitualmente, dicha elección es precedida por la formulación de algunas preguntas significativas a las que intentar dar una respuesta: ¿qué hace que este lugar sea especial o distinto de los demás? ¿Qué es lo importante del paisaje que se analiza? ¿Qué echaría de menos si ya no estuviera? ¿Qué quisiéramos para el futuro de este patrimonio? ¿Hay lugares singulares de los que se cuentan historias, leyendas? ¿Hay sitios que son o han sido importantes en la vida de la localidad o en su propia vida personal? ¿Cómo ha cambiado el lugar en el tiempo de su memoria? ¿Qué se podría preservar, mejorar o transformar? ¿Cuál es el valor más compartido por la población?

Entre las primeras y principales metodologías adoptadas en la fase de indagación están las entrevistas y los cuestionarios, dirigidos especialmente a los miembros de la comunidad. También la opinión de quien es externo, de quien frecuenta el lugar, aunque no vive en él, es fundamental, ya que hace surgir un "otro punto de vista", desinteresado y carente de toda implicación emocional o afectiva.

Los cuestionarios se configuran como herramientas no demasiado engorrosas y pueden ser la solución más adecuada en caso de una generalizada desconfianza hacia prácticas de implicación más "entrometidas".

Las entrevistas, aun pudiendo plantearse también como herramientas bastante formales y despegadas, por el solo hecho de conllevar una relación entre entrevistador y entrevistado, involucran más a la persona. Estas últimas revelan todo su potencial allí donde "salen de los esquemas preestablecidos" para seguir el fluir de los relatos y adentrarse en las memorias. A tal propósito, Aldo Summa habla de la estimulación de "historias invisibles, poniéndose al servicio y en la condición de la escucha, suscitando dinámicas de reactivación" (Summa, n.d.).

También otros tipos de investigación entran a formar parte de la trayectoria, transformándose a menudo de modalidades tradicionales y ordenadas de indagación a modalidades caóticas, pero de todas formas fecundas. Constituyen un ejemplo las 
investigaciones de archivo para la consulta de las publicaciones (literarias, fotográficas o cinematográficas) inherentes a los temas tratados, cuando la implicación toma la delantera.

Los materiales recogidos mediante estas y otras muchas estrategias, son después compartidos dentro del grupo de investigación y debatidos.

En todas las fases anteriormente citadas, es conveniente trabajar por grupos de interés (es decir, por grupos cuyos componentes comparten la pasión por un determinado tema), de modo que la búsqueda esté impulsada por una verdadera motivación al descubrimiento (motivación de tipo intrínseco).

Gracias al trabajo de investigación y de análisis del patrimonio cultural local que hay que representar en el mapa de comunidad, se realizan varios encuentros encaminados a la reflexión sobre los conocimientos que han surgido. Una reflexión que, al final de la trayectoria, conducirá a la conquista de un saber comunitario y, en consecuencia, a la definición de las modalidades con que representarlo.

Para alcanzar semejante objetivo, es necesario trabajar durante largo tiempo y en profundidad. También en este caso, recurrir a particulares estrategias participativas puede resultar muy útil. De poco servirían una lista de los conocimientos recopilados, la lectura de una historia de vida transcrita en una libreta, la explicación de las secuencias de un trabajo tradicional. Mucho más eficaz sería la utilización de metodologías capaces de estimular la participación y la contribución de todos, como el brainstorming y el role playing ${ }^{10}$ (Testa, 2007).

Llegados al final -nunca realmente tal- del trabajo de investigación e interpretación del patrimonio cultural, no queda más que decidir cuál es la mejor solución para representarlo y restituirlo, así, a la más amplia comunidad a que pertenece. En realidad, de forma deseable, los momentos de restitución deberían ser más de uno, diseminados a lo largo de la trayectoria de proyectación. De esta manera, incluso los miembros de la población que no han tomado parte en la actividad de trazado del mapa del territorio, adquirirían una mayor conciencia y capacidad de comprensión de los resultados obtenidos.

El hecho de que se hable de mapas de comunidad y del trabajo asociado a los mismos no debe inducir a engaño, haciendo pensar que el único y exclusivo sistema de restitución es la realización de un mapa. En verdad, las formas que puede asumir la representación del patrimonio local identificado son variadas y diversificadas:

- Un espectáculo teatral, donde la comunidad asiste a la "puesta en escena" de relatos, conocimientos y memorias del territorio (Rossi Ghiglione, 2004, p. 33-34).

- Una realización de video, capaz de ir más allá de la mera documentación y de volver animado el patrimonio descrito (Zambon, 2004, p. 35-36).

- Una representación gráfica, como un mapa o similar.

- Una fiesta pública, en forma de evocación histórica, con representaciones, animación, cocina típica y así sucesivamente.

- La creación de sitios web o de revistas dedicadas.

- Etcétera.

10 El brainstorming, literalmente "tormenta del cerebro" (o tormenta de ideas) consiste en recoger las intuiciones espontáneas de los participantes en forma de palabras clave, de donde surgirá una conversación encaminada a la reflexión, de grupo además de personal. El role playng (o juego de rol) consiste en una simulación interpretativa donde los participantes se asumen papeles que no les pertenecen. Esto, además de ejercitar habilidades sociales, emocionales y cognitivas, favorece una comprensión más profunda de las situaciones y su interiorización. 
Por consiguiente, cada contexto comunitario puede elegir entre una infinita variedad de modalidades representativas, en función de sus características, posibilidades y necesidades.

\section{REFERENCIAS BIBLIOGRÁFICAS}

Arnstein, S. R. (1969). A Ladder of Citizen Participation. Journal of the American Planning Association, 35(4), 216-224.

Barbieri, G., Canigiani, F., \& Cassi, L. (2003). Geografia e cambiamento globale. Le sfide del XXI secolo. Torino: UTET.

Bazzini, D. (2004). Ci sono ancora i luoghi e le comunità?. Signum, mappe di comunità, 1, 13-20.

Bonacchi, S. (n.d.). Ecomuseo: verso una Nuova Museologia. La realtà museale a confronto con la Postmodernità. Recuperado de www.psicolab.net/index.asp?pid=idart\&cat10\&scat=149\&ar id $=2231-49 \mathrm{k}$

Castellari, G. (n.d.). Mappe di comunità come strumento di valorizzazione del territorio. Presentazione delle mappe culturali del territorio ferrarese. Recuperado de http://www.ibc.regione.emiliaromagna.it

Clifford, S., \& King, A. (2006). England in particular. London: Saltyards Books.

Clifford, S., Maggi, M., \& Murtas, D. (2006). Genius Loci. Perché, quando e come realizzare una mappa di comunità. Torino: Istituto di Ricerche Economico Sociali del Piemonte.

Consejo de Europa. (2000). Convenio Europeo del Paisaje. Recuperado de http://www.bap. beniculturali.it/attivita/tutela_paes/convenzione.html

Davis, P. (1999). Ecomuseums: a sense of place. Newcastle: Bloomsbury Academic.

De Varine, H. (2010). Per gestire insieme il nostro patrimonio sul territorio. Recuperado de http://mappadicomunita.it

Donato, F. (2010). Le amministrazioni pubbliche verso logiche di governo partecipato. Milano: Giuffrè.

Giorda, C. (2014). Il mio spazio nel mondo. Geografia per la scuola dell'infanzia e primaria. Roma: Carocci.

Hoara, K. (1998). The image of Ecomuseum in Japan. Pacific Friends, 25/12.

IRES Piemonte. (2000). Gli ecomusei. Che cosa sono, cosa possono diventare. Working Paper $n^{o}$ 137, 1-108.

Luisetti, F. (2004). Il bisogno di mappe e l'assenza comunitaria. Signum, mappe di comunità, 2(55).

Maggi, M. (2002). Ecomusei. Guida europea. Torino, Londra, Venezia: Allemandi.

Maggi, M. (2008). Perché si fanno le mappe di comunità. Informe desarrollado en Ospedaletto (Gemona del Friuli) el 5 de abril de 2008 en el marco de los seminarios de formación previstos por el proyecto "Mapa de comunidad". Recuperado de http://www.mappadicomunita.it

Magnaghi, A. (2010). Il progetto locale. Verso la coscienza di luogo. Torino: Bollati Borlinghieri.

Musci, E. (2015). Il paesaggio storico-culturale nei musei tra allestimenti e interfaccia didattica. Una ricerca in Italia e in Spagna. Il Capitale culturale. Studies on the Value of Cultural Heritag, XI, 275-311.

Muscò, D. (Ed.). (2007). L'ecomuseo tra valori del territorio e patrimonio ambientale. Briciole, 1114, 1-160.

Pidello, G. (2004). Zone di contatto. Signum, mappe di comunità, 2.

Rivière, G.H. (1992). Territoires de la mémoire, les collections du patrimoine ethnologique dans les ècomuées (dirección M. Augè, Retomado de: La Muséologie selon Georges Henri Rivière, 1989). Paris: Éditions de L'ALBARON.

Rossi Ghiglione, A. (2004). Terre di racconti: ecco i segreti dei raccoglitori di storie. Signum, mappe di comunità, 2, 33-34. 
Sturani, M.L. (2009). Paesaggio e musei: esplorazione critica di modelli. In Le ragioni del museo. Temi, pratiche e attori (pp. 117-153). Ivrea: Fondazione Adriano Olivetti.

Sturani, M.L., \& Pressenda, P. (2015). Ecomusei e paesaggio: una nuova opportunità per la tutela e la valorizzazione nel contesto italiano?. Rivista Geografica Italiana, 113, 73-97.

Summa, A. (n.d.). La costruzione di una mappa di comunità. In Le mappe di comunità nel piano paesaggistico territoriale della regione puglia (p. 29). PPTR. Recuperado de http://paesaggio. regione.puglia.it/images/stories/Mappe_COMUNIT/mappe_comunita_dossier.pdf

Testa, R. (2007). Il progetto di fattibilità e la gestione dell'ecomuseo. Briciole, 11-14.

UNESCO. (2003). Convención para la Salvaguardia del Patrimonio Cultural Inmaterial. París. Recuperado de http://unesdoc.unesco.org/images/0013/001325/132540s.pdf

Zambon, L. (2004). Narratori dei luoghi: del gerbido e della vigna. Signum, mappe di comunità, 2 , 35-36. 
